\title{
A survey on relationship between customer satisfaction and electronic banking features: A case study of Tejarat bank in Iran
}

\author{
Hasan darvish $^{\mathrm{a}^{*}}$, Mohammad Reza Moayeri ${ }^{\mathrm{b}}$, Mohamad Malekmohamadi Faradonbe ${ }^{\mathrm{c}}$ and Ali Reza \\ Naderifar $^{\mathrm{d}}$
}
${ }^{a}$ Department of Economy,Management And Accounting,Payam Noor University, Tehran,Iran
${ }^{b}$ Master of Business Administration, Payam Nour University, Gheshm, Iran
${ }^{c}$ Department of Public Administration, Azad University of Dehaghan, Esfahan,Iran
${ }^{d}$ Department of Public Administration, Zahedan, University, Zahedan, Iran

\section{H R O N I C L E A B S T R A C T}

Article history:

Received October 14, 2012

Received in revised format

24 December 2012

Accepted 5 January 2012

Available online

January 72013

Keywords:

Customer satisfaction

Electronic banking

Tejarat bank

\begin{abstract}
Customer satisfaction plays an important role on the success of banking industry. A customer may switch his/her primary banking from one to another as soon as he/she is unsatisfied from the quality of services. In this paper, we study the impact of six factors on electronic banking including easy access, design, transaction speed, security, information content and customer support on customer satisfaction. The proposed study was performed in different branches located in north east of city of Tehran, Iran named Tejarat. The study selected a sample of 200 customers, designed, and distributed a questionnaire among them. The results of our survey have indicated that all six components significantly influenced on customer satisfaction. We have also investigated a linear regression between the six independent variables and customer satisfaction and using stepwise linear regression technique the most suitable regression model. The results of regression analysis have also indicated that an increase of one unit in easy access, information content and customer support will increase customer satisfaction by $0.201,0.368$ and 0.356 , respectively.
\end{abstract}

\section{Introduction}

Today, customer is the primary key success on many industries including banking industries. The emerge of private banks in some developing countries such as Iran has increase competition among business owners to think more about the quality of their services and introduce electronic banking features in an attempt to have better customer retention and absorb more customers through getting more market share. In such circumstances, quality of services plays an important role for the success of business owners. Zarei et al. (2012) presented a multi criteria decision making method along with Kano method to rank the most influencing factors of service quality in one of the oldest banks in Iran

*Corresponding author.

E-mail addresses: dr_darvish@pnu.ac.ir (H.Darvish) 
called Sepah. They collected various factors impacting customer satisfaction for all Sepah banks located in Semnan, Iran and using, analytical hierarchy process provided a detailed ranking.

Tajzadeh Namin et al. (2012) made an assessment on the quality of services of Tehran's Saman bank and the available gap between customer's expectation and perception. They also investigated the relationship between customer's satisfaction and each dimension of service quality including reliability, tangibility, responsiveness, assurance and empathy in a private bank in Tehran, called Saman. The results from a sample of 276, demonstrated that the service quality dimensions influenced customers' perception based on SERQUAL (Buttle, 1996) and there were significant relationship between customers' perception and their satisfaction of the offered services and there were negative gaps between customers' perception and their level of expectation.

Gazor et al. (2012) studied the relationship between customer perceptions from service encounter quality and loyalty of customer to organization and employees. They implemented the model for banking sector in Iran using SERVQUAL (Lages \& Fernandes, 2005) factors and considered different factors impacting the quality of service. The results of the survey indicated that service quality systems, customer satisfaction were the most desirable factors based on the feedback they received from the customers. Besides, response to customers and loyalty to employees, service encounter quality, service and loyalty to organization, arrangements were in the next levels, respectively.

Jomehri et al. (2012) studied the impacts of customer value, customer satisfaction and customer loyalty on customer retention. The results demonstrated that all aspects of the customer value had positive relationships with customer satisfaction but only emotional value had a positive and direct relationship with customer loyalty. The study confirmed that while none of customer value aspects had direct and positive relationship with customer retention, both customer satisfaction and customer loyalty positively and directly influenced customer retention. Darvish et al. (2012) explained that, many banks try to move from traditional banking system to entrepreneurial one to create new opportunities. They reported that the entrepreneurial orientation, cultural factors and among organizations factors, making proper connections between organizational unit and high manager support had a good condition in some Iranian banking industry.

Gharli Ronizi and Gharli Ronizi (2012) presented a study on employees of an Iranian private bank to find important factors impacting creative habits based on Pearson correlation test. They reported that sense of being effective was number one priority followed by sense of competence and sense of being meaningful and sense of choice. Khodaei Valahzaghard et al. (2012) the impacts of related services to support employee to reach job satisfaction and employee activities in one of Iranian banks called Mellat bank was and the results indicated that employees were relatively satisfied from the benefit package of the bank.

In this paper, we study the impact of six factors on electronic banking including easy access, design, transaction speed, security, information content and customer support on customer satisfaction. The organization of this paper first presents the proposed hypotheses in section 2, the results are explained in section 3 and the paper ends with concluding remarks.

\section{The proposed study}

The proposed study of this paper designs questionnaire in Likert scale, which includes 23 questions. The study targets all potential customers who reside in North East part of city of Tehran, Iran and may do online banking with Bank Tejarat. The sample size is calculated as follows,

$$
N=Z_{\alpha / 2}^{2} \frac{p \times q}{e^{2}},
$$


where $N$ is the sample size, $p=1-q$ represents the probability, $z_{\alpha / 2}$ is CDF of normal distribution and finally $\varepsilon$ is the error term. For our study we assume $p=0.5, z_{\alpha / 2}=1.96$ and $e=0.98$, the number of sample size is calculated as $N=196$. In this survey, we have distributed 200 questionnaires among the participants. Cronbach alpha has been calculated as $95.72 \%$, which validates the overall performance of the questionnaire. Fig. 1 shows some statistics about the participants' age.

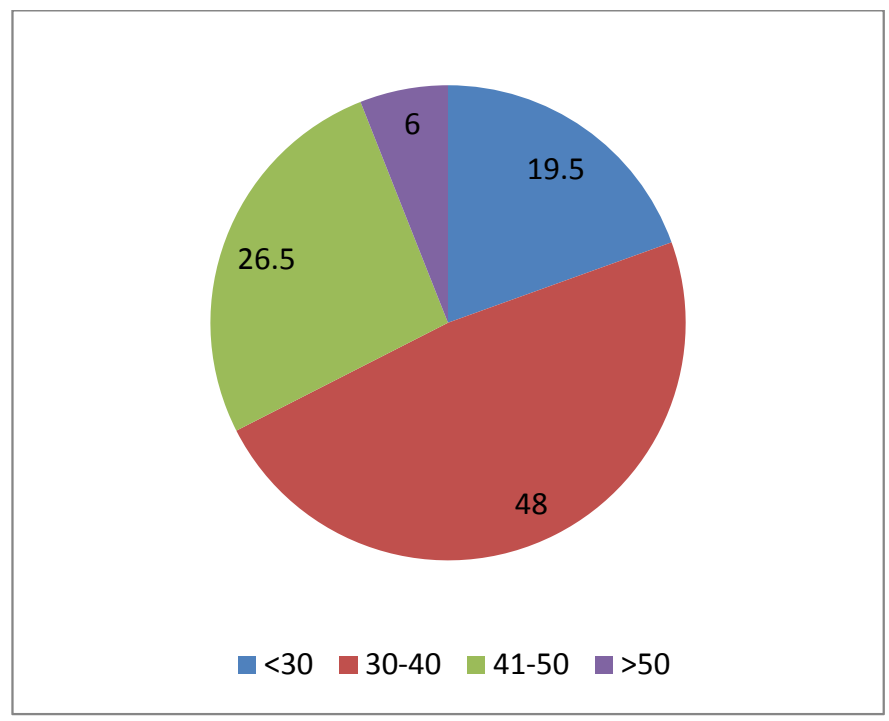

Fig. 1. Participants’ age

As we can observe from Fig. 1, most participant are in middle age, where $48 \%$ were aging between 30 to 40 and 26.5\% were between 41-50 years. In addition, Fig. 2 and Fig. 3 demonstrate some basic statistics of the participants in terms of educational background as well as years of experience in online banking.

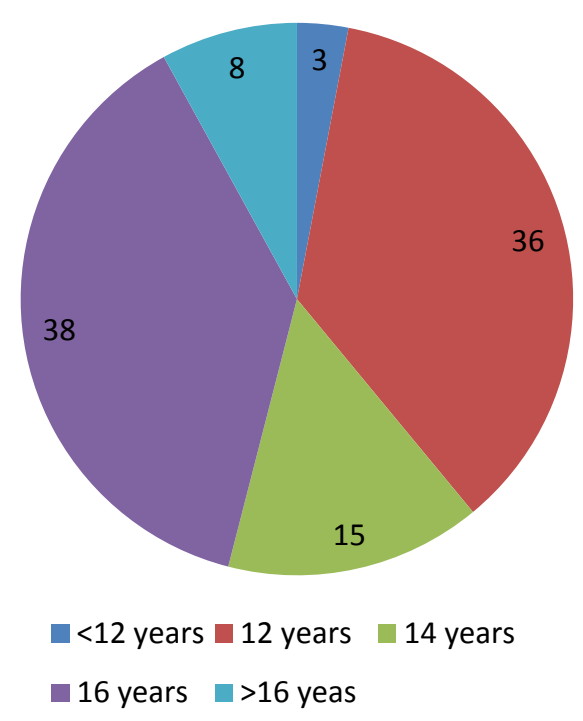

Fig. 2. Participants' years of educations

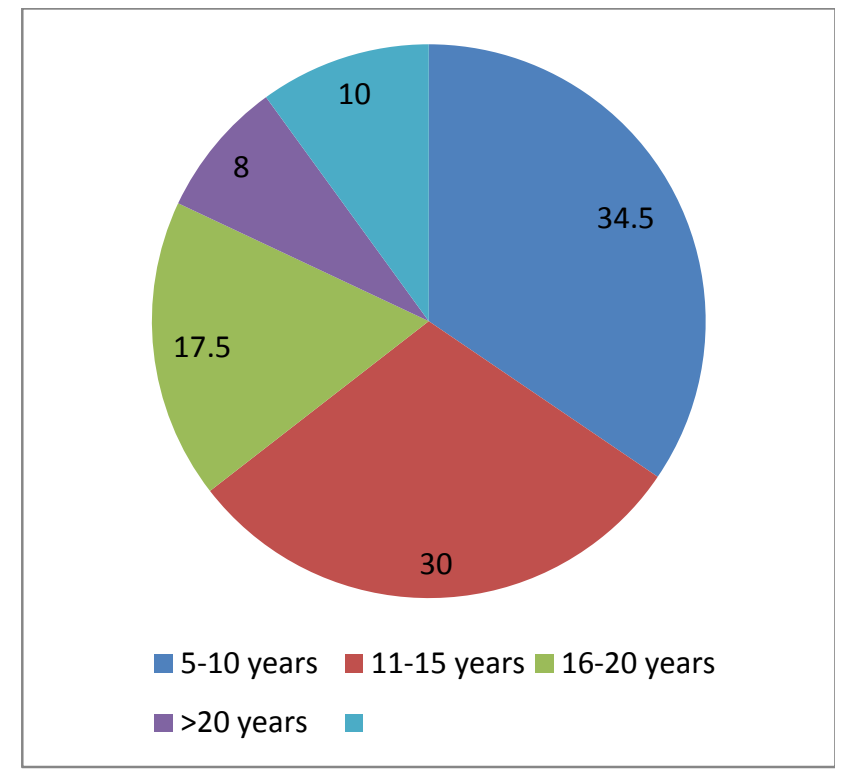

Fig. 3. Participants' years of electronic banking 
In this study, $57 \%$ of the participants were male and the rest of $43 \%$ were female. In addition, $26 \%$ of them were single and $74 \%$ were married. The normality test yields that none of the variables is normally distributed and we may use non-parametric test to examine hypotheses.

Fig. 4 shows details of the framework of the proposed study. As we can observe from Fig 4, we study the impact of six factors on electronic banking including easy access, design, transaction speed, security, information content and customer support on customer satisfaction.

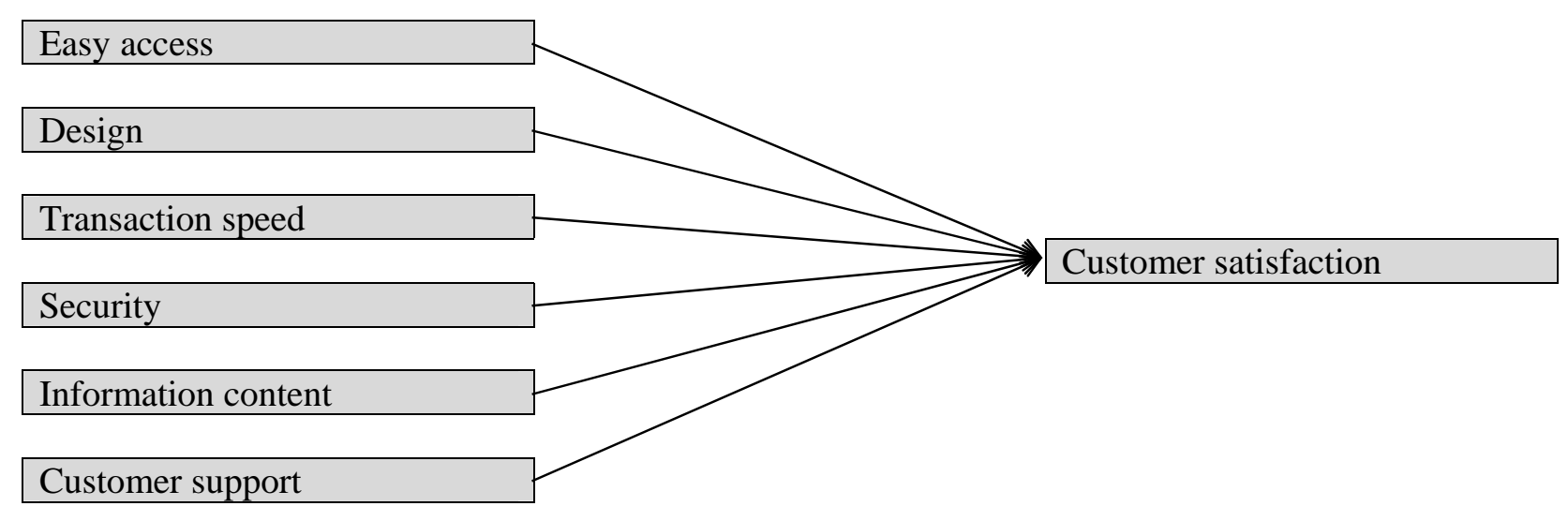

Fig. 4. The framework of the proposed study

\section{The results}

As stated earlier, the proposed study of this paper needs to use non-parametric tests to examine the effects of six hypotheses of this paper. In our study, we use Pearson correlation test to examine all hypotheses.

\subsection{The first hypothesis: Easy access and customer satisfaction}

The first hypothesis of the survey investigates whether there is any relationship between easy access to electronic banking and customer satisfaction. The Pearson correlation test yields 0.649 with Sig.= 0.000. Therefore, we can conclude that there is a meaningful and positive relationship between these two items and the first hypothesis is confirmed.

\subsection{The second hypothesis: Design and customer satisfaction}

The second hypothesis of the survey investigates whether there is any relationship between a good web design in electronic banking services and customer satisfaction. The Pearson correlation test yields 0.631 with Sig. $=0.000$. Therefore, we can conclude that there is a meaningful and positive relationship between these two items and the second hypothesis is confirmed.

\subsection{The third hypothesis: Transaction speed and customer satisfaction}

The third hypothesis of the survey investigates whether there is any relationship between transaction speed of electronic banking and customer satisfaction. The Pearson correlation test yields 0.684 with Sig. $=0.000$. Therefore, we can conclude that there is a meaningful and positive relationship between these two items and the third hypothesis is confirmed.

\subsection{The fourth hypothesis: Security and customer satisfaction}

The fourth hypothesis of the survey investigates whether there is any relationship between transaction security in electronic banking and customer satisfaction. The Pearson correlation test yields 0.588 
with Sig. $=0.000$. Therefore, we can conclude that there is a meaningful and positive relationship between these two items and the fourth hypothesis is confirmed.

\subsection{The fifth hypothesis: Information content and customer satisfaction}

The fifth hypothesis of the survey investigates whether there is any relationship between information content in electronic banking and customer satisfaction. The Pearson correlation test yields 0.743 with Sig. $=0.000$. Therefore, we can conclude that there is a meaningful and positive relationship between these two items and the fifth hypothesis is confirmed.

\subsection{The sixth hypothesis: Customer support and customer satisfaction}

The sixth hypothesis of the survey investigates whether there is any relationship between information customer support in electronic banking and customer satisfaction. The Pearson correlation test yields 0.776 with Sig. $=0.000$. Therefore, we can conclude that there is a meaningful and positive relationship between these two items and the last hypothesis is confirmed.

In summary, all hypotheses of this survey have been confirmed and we can conclude that there is a positive relationship between easy access, design, transaction speed, security, information content and customer support from one side and customer satisfaction on the other side. We have also investigated a linear regression between the six independent variables and customer satisfaction and using stepwise linear regression technique the most suitable regression model. The results of our survey is as follows,

Customer satisfaction $=0.201 \times$ Easy access $+0.368 \times$ Information content $+0.356 \times$ Customer support .

Based on the results of regression analysis, an increase of one unit in easy access, information content and customer support will increase customer satisfaction by $0.201,0.368$ and 0.356 , respectively. In other words, the regression analysis indicates that information content plays the most important impact followed by customer support and easy access comes last in our ranking.

\section{Conclusion}

In this paper, we have explained how competition has influenced banking industry in Iran and discussed why it is important for Iranian banks to use the recent advances of information technology to provide better services through online banking to increase customer satisfaction. The results of our survey have indicated that easy access to online banking, web design, transaction speed, security, information content and customer support could influence on customer satisfaction. The results of regression analysis have also indicated that an increase of one unit in easy access, information content and customer support will increase customer satisfaction by $0.201,0.368$ and 0.356 , respectively. In other words, the regression analysis indicates that information content plays the most important positive impact followed by customer support and easy access comes last in our ranking.

\section{References}

Buttle, F. (1996). SERVQUAL: review, critique, research agenda. European Journal of Marketing, 30(1), 8-31.

Cronbach, L. J. (1951). Coefficient alpha and the internal structure of tests. Psychometrika, 16(3), 297-334.

Darvish, H., Alvani, S.M., salehi sadagiani, J., \& Abbaszadeh, H. (2012). An empirical study on effective factors on entrepreneurial orientation in Iranian banking industry. Management Science Letters, 2(7), 2591-2600. 
Gazor, H., Nemati, B., Ehsani, A., \& Nazari Ameleh, K. (2012). Analyzing effects of service encounter quality on customer satisfaction in banking industry. Management Science Letters, 2(3), 859-868.

Gharli Ronizi, N., \& Gharli Ronizi, Z. (2012). A study on different factors impacting creative habits. Management Science Letters, 3(1), 329-336.

Jomehri, N., Javanshir, H., \& Ebrahim Nezhad, S. (2012). An empirical study to determine the critical success factors on customer retention: A case study of Iranian banking sector. Management Science Letters, 1(2), 223-234.

Khodaei Valahzaghard, M. Afzali, F., \& Khodaei Valahzaghard, S. (2012). An empirical study on the effects of human resource supporting strategies on job satisfaction. Management Science Letters, 2(5), 1535-1542.

Lages, L. F. \& Fernandes, J.C. (2005). The SERPVAL scale: A multi-item instrument for measuring service personal values. Journal of Business Research, 58(11), 1562-1572.

Likert, R. (1932). A Technique for the Measurement of Attitudes. Archives of Psychology, 140, 1-55.

Tajzadeh Namin, A., Pilevary, N., \& Tajzadeh Namin, A. (2012). Measuring customer satisfaction using SERQUAL survey. Management Science Letters, 2(3), 933-938.

Zarei, A., Hemati, M., \& Rafeeian, M. (2012). Prioritizing the effective factors for customers attraction: A case study of Sepah Bank. Management Science Letters, 2(3), 961-970. 